\title{
Eisenbestimmung im Serum (Plasma) mit Tripyridyl-triazin (TPTZ) und Citratpuffer. Bewertung der Methode sowie Anpassung an einen SMAC II und RA-1000
}

\author{
U. B. Seiffert', E. Solem², M. Zirker' \\ - Zentrallabor des Zentrums der Inneren Medizin \\ 2 Klinisches Labor des Zentrums der Kinderheilkunde, Klinikum der Johann Wolfgang Goethe-Universität, Frankfurt
}

Zusammenfassung:

Die TPTZ-Citrat-Methode für die Eisenbestimmung im Serum bzw. Plasma zeichnet sich durch verschiedene Vorteile gegenüber anderen handelsüblichen Methoden aus.

1. Der Eisennachweis wird nur zu $2 \%$ durch Kupfer falsch-positiv gestört.

2. Die Farbreaktion erfolgt in Citratpuffer bei einem pH von 2,1 bis 2,5. Dieses Milieu ist günstig für die Freisetzung von Eisen aus der Transferrinbindung und gleichzeitig optimal für die Farbentwicklung. Es verhindert in der Regel Proteinpräzipitation, so daß ohne Enteiweißung gemessen werden kann. Die Freisetzung von Eisen aus Hämoglobin wird minimiert. Die Automation dieses Eisentests ist unproblematisch.

3. Die TPTZ-Citrat-Methode ist kostengünstig im Vergleich zu handelsüblichen Tests. Auf Reagenzienbasis reduziert sich der Preis pro Analyse auf $1 / 4$ bis $1 / 10$.

Schlüsselwörter:

Eisenbestimmung - Tripyridyltriazin (TPTZ) - Citrat

Summary:

This method for iron estimation deserves special attention.

1. The specificity for iron is high. The influence of copper is approximately $2 \%$ only in comparison to methods using ferrozine (up to 15\%). Hemoglobin-iron does not disturb the measurement of plasma or serum iron.

2. The reaction is performed in citrate buffer at a pH from 2.1 to 2.5. This $\mathrm{pH}$ is optimal for the liberation of iron from transferrin. At this $\mathrm{pH}$ with serum, no precipitation occurs. Thus, a direct photometry is possible without previous protein precipitation. Since this $\mathrm{pH}$ is also optimal for colour development, the complete reaction can be accomplished in one step and automation of analysis can easily be performed.

3. This test can be performed at low cost. Compared to commercial tests, the price can be reduced between $1 / 4$ and $1 / 10$.

Keywords:

Iron estimation - Tripyridyltriazin (TPTZ) - citrate

\section{Einleitung}

In den letzten Jahren wurden verschiedene Chromogene, meistens Phenanthrolin-Derivate, für die Eisenbestimmung im Serum untersucht und angeboten (1-4). Eine Methode mit eindeutigen Vorteilen hat sich nicht finden lassen. Wir haben diese Problematik erneut aufgegriffen und untersucht, weil täglich immer wieder einzelne Ergebnisse der Eisenbestimmung mit dem Krankheitsbild des Patienten nicht übereinstimmten (5).

Die Eisenanalytik in Serum bzw. Plasma ist vielschichtig und kompliziert. Nicht nur die Spezifität der Farbbildung, sondern auch die Freisetzung von Eisen aus verschiedenen Verbindungen mit Proteinen und Chelatbildnern geht in die Analyse mit ein. Daher müssen alle chemisch-analytischen Teilschritte der gesamten Reaktionskette opti- mal aufeinander abgestimmt sein. Wichtige Einflußgrößen auf die Bestimmung von Eisen im Serum sollen kurz erörtert werden.

Die Freisetzung von Eisen aus der Transferrinbindung wird mit Mineralsäuren sicher erreicht $(6,7)$, während die Transferrin-Eisen-Bindung im alkalischen Milieu stabil ist (8). Unklar blieb bisher die Stärke der Säure. Säurebehandlung mit $\mathrm{pH}-$ Werten $<2$ hat Nachteile, weil Trübung und/oder Pigmentbildung auftritt und die Farbbilfung geţiemmt wird (1). Die vollständige Freisetzung von Eisen aus der Transferrinbinding ohne den Einsatz mineralischer Säuren ist ein Kompromiß. Sie.soll durch geeignetes Chromogen, durch chaotrope Reagenzien $(9,10)$, durch Reduktionsmittel und/oder Detergentien unterstützt werden $(1,11,12)$. Detergentien vermindern auch Trübung durch Lipide und Protein (13). 


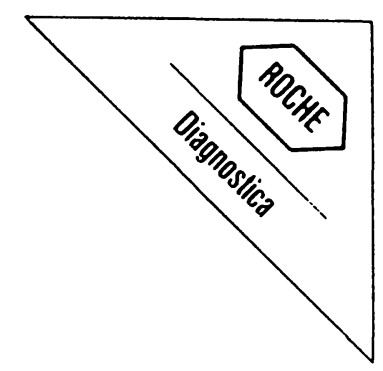

\section{arm}
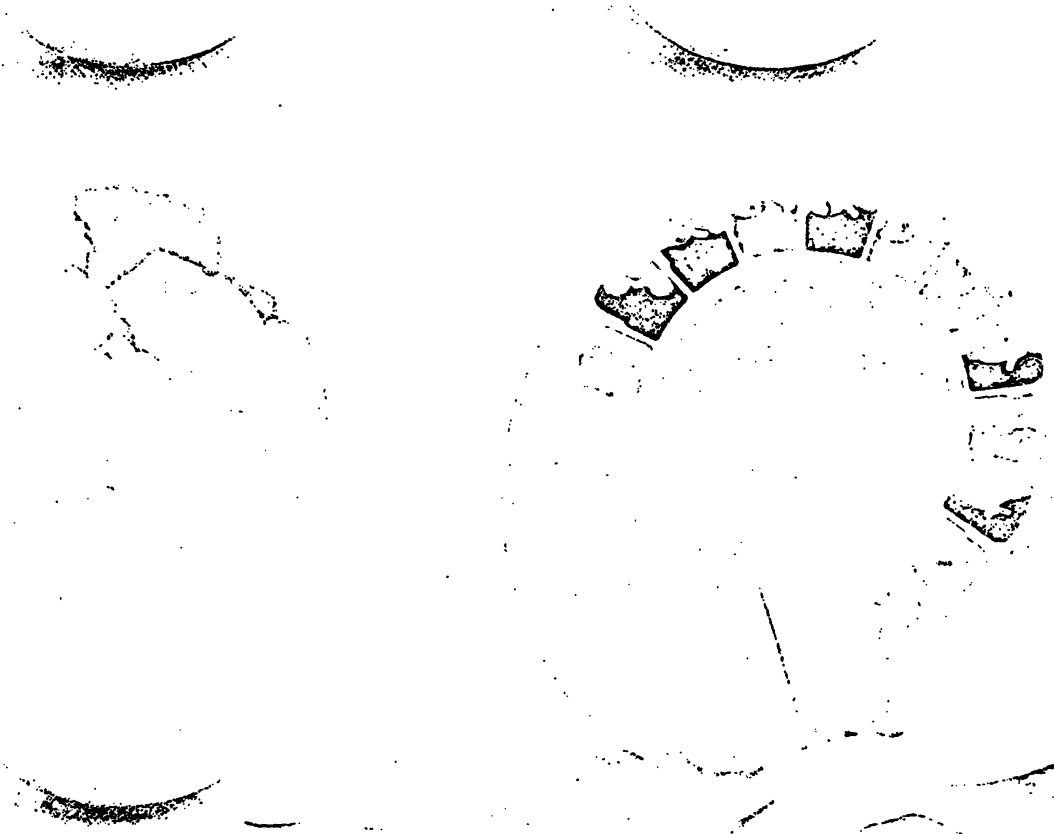

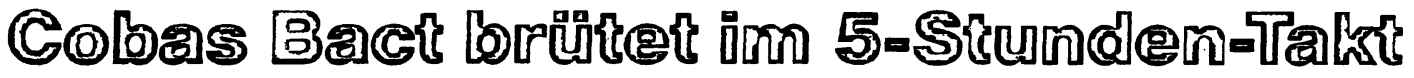

Cobas Bact ist ein automatisiertes System zur schnellen Empfindlichkeitsprüfung und Identifikation häufig auftretender Infektionserreger für das mikrobiologische Labor.

Empfindlichkeitsprüfungen sind schon nach 5 Stunden, die Identifizierung von Enterobacteriaceae bereits nach 4 Stunden durchgeführt und ausgewertet.

Darüber hinaus unterstreichen folgende Punkte eindrucksvoll die Leistungsfähigkeit des Cobas Bact Systems:

\section{Empfindlichkeitsprüfung}

- Standardisierte, kinetische Wachstumsmessung

- Reproduzierbare Auswertung

- Zwischenergebnisse jederzeit als Extinktion der Wachstumskurven abrufbar

- Individuelle, aktuelle und flexible Antibiotika-Zusammenstellung für Antibiogramme
2. Identifizierung der Enterobacteriaceae

- Biochemische Reaktionen

- Biocode-Ausdruck zur Plausibilitätsprüfung

\section{EDV-Kompatibel}

- Integriertes Interface

Für weitere Informationen und Erprobungstermine stehen wir Ihnen gerne zur Verfügung.

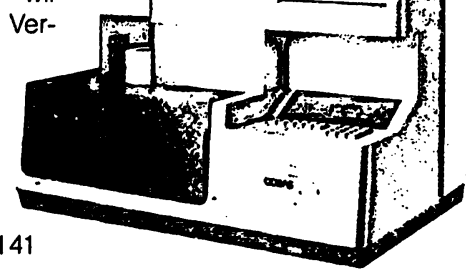




\section{Die lhöchst zuverlässige Familliee von Elelktrolyt-A mallysatoren。}

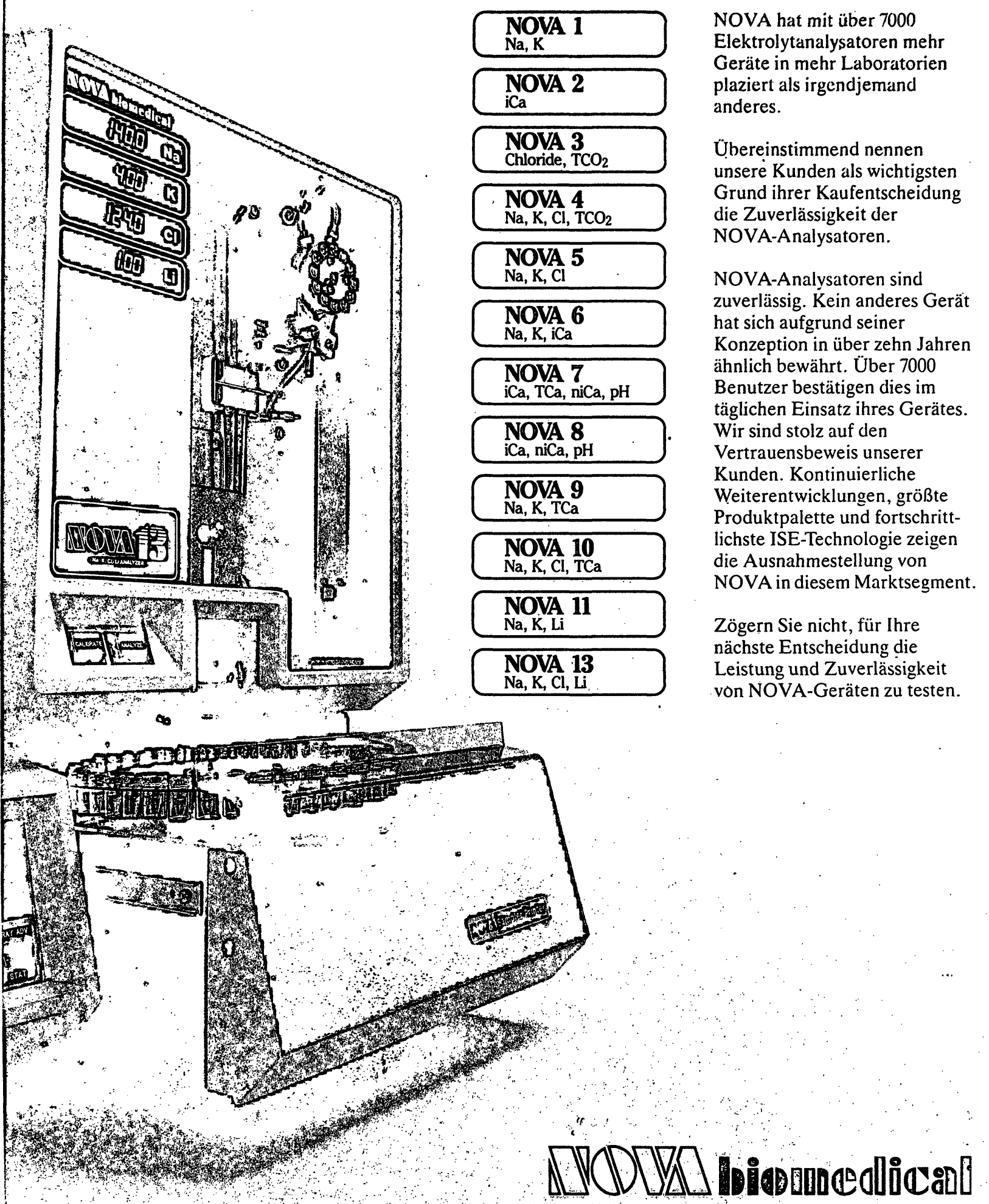


Eisen kann unter bestimmten Umständen aus Hämoglobin freigesetzt werden, wodurch falsch-positive Ergebnisse erhalten werden $(3,11,14)$. Im alkalischen Milieu wird Eisen aus Hämoglobin leichter gelöst (3). Aus diesem Grunde scheidet eine. Eisenbestimmung im alkalischen Milieu aus $(1,3)$.

Eisen im Serum kann auch an andere Proteine als Transferrin gebunden sein $(15-17)$. Schwermetalle und Chelatbildner (z. B. EDTA) stören die Freisetzung von Eisen (16). Das wird vereinzelt bei Patientenproben störend deutlich.

Die Farbbildung aus Chromogen und Eisen ist vom $\mathrm{pH}$, der lonenkonzentration, der Art des Puffers u.a. abhängig. In bezug auf die Spezifität und Empfindlichkeit des Eisennachweises muß das Milieu optimal sein. Bei direkten Verfahren muß dieses Milieu gleichzeitig auch für die Freisetzung von Eisen optimal sein $(1-4)$.

Kupferionen reagieren mit den Chromogenen in unterschiedlichem Maße. Absolut Eisen-spezifische Chromogene sind nicht bekannt $(6,13,18,19)$. Im allgemeinen wird diesem Punkt zu wenig Beachtung geschenkt. In einigen Methoden wird Kupfer chemisch eliminiert, jedoch nicht vollständig $(3,13,19,20)$. Ferrozin sollte aus diesem Grund für direkte Methoden nicht verwendet werden.

Protein-Präzipitate, die die Photometrie stören, werden durch Enteiweißen oder bei continuous-flow-Systemen durch Dialyse vermieden $(1,10,21)$. Enteiweißen hat aber auch Nachteile: Eisen kann co-präzipitieren, bei der Dialyse kann der Gibbs-Donnan-Effekt zu falsch niedrigen Resultaten führen. Bei sehr niedrigen $\mathrm{pH}$-Werten kann Eisen aus Hämoglobin gelöst werden sowie Pigment und Trübung entstehen $(6,20,21)$.
Methodisch ist es nicht möglich, alle Vorteile zu nutzen und alle Nachteile zu vermeiden, welcher Farbstoff auch zum Einsatz gelangt. Man wird einen Kompromiß schließen müssen. Die Auswahl sollte auch praktische $\mathrm{Ge}$ sichtspunkte berücksichtigen.

Wir haben Tripyridyltriazin als Chromogen in Verbindung mit Citratpuffer und Ascorbinsäure eingesetzt. Es handelt sich um ein Chromogen, das schon lange dem Nachweis von Eisen dient $(1,4)$. In Verbindung mit Citratpuffer werden Nachteile vermieden, die bisher seinem Einsatz in der Routine im Wege standen. TPTZ ist nur unwesentlich geringer empfindlich für Eisen als Ferrozin. Diese Methode wurde kürzlich neu bearbeitet (5).

\section{Material und Methoden}

\section{Probenmaterial}

Seren bzw. Heparin-Plasmen wurden vom gleichen Tage verwendet.

Für die Methodenvergleiche wurden drei Kollektive zusammengestellt. Kollektiv A sind wahllos aus der klinischen Routine herausgegriffene Proben. Kollektiv B sind Proben, die mindestens einen deutlich pathologischen, biochemischen Parameter enthielten (Bilirubin, Kreatinin, Harnstoff, Glukose, GOT, Cholesterin). Kollektiv C besteht aus Proben mit einem Eisengehalt $<50 \mu \mathrm{g} / \mathrm{dl}$.

Die Kollektive für die Normbereiche bestanden aus $\mathrm{Pa}$ tienten der Poliklinik, die klinisch und biochemisch keinen krankhaften Befund aufwiesen.

Hämoglobin wurde nach osmotischer Lyse der Erythrozyten gewonnen und einigen Proben beigemischt.
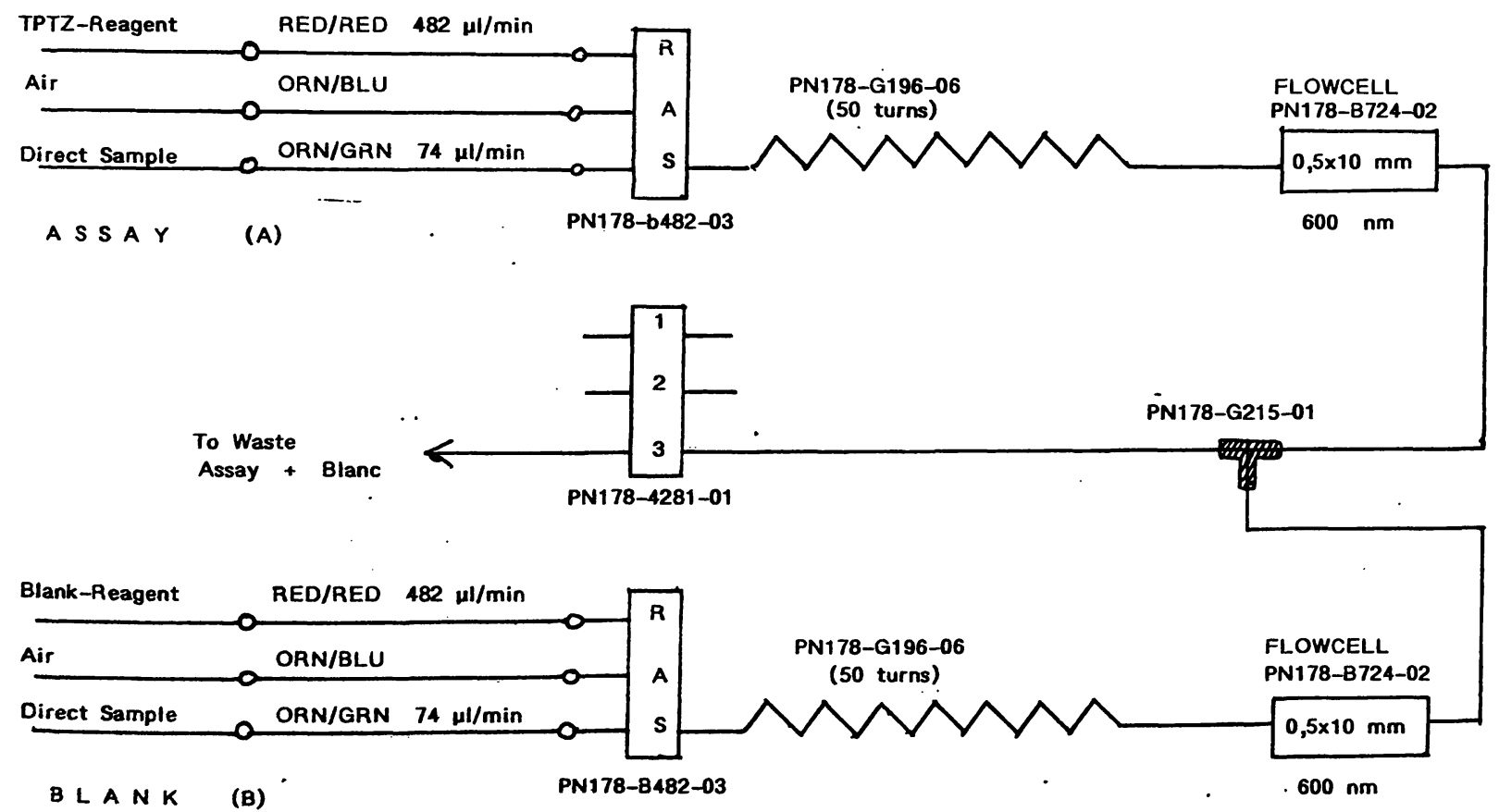

Abb.1: Fließdiagramm für die TPTZ-Citrat-Eisenmethode am SMAC II (TECHNICON). Abkürzungen und Einzelheiten nach Vorschrift des Herstellers 
Tab. 1: Programmvorschlag für die TPTZ-Citrat-Eisenmethode am RA-1000 (TECHNICON). Abkürzungen und Einzelheiten (") nach Vorschrilt des Herstellers

\begin{tabular}{lc} 
Programm: & ()$\left.^{\circ}\right)$ \\
MTH NR. & 31 EISEN \\
NAME & 2 \\
TYP & 60 \\
\%PR VOL & $6 \mathrm{WL} 600$ \\
FILTER POS & 200 \\
TOTZ. & 75 \\
LW.REAG. & $9 \mathrm{\mu g} / \mathrm{DL}$ \\
\%REAG.VOL & 1,0 \\
EINH & 0 \\
UNIT FAC & 0,0 \\
DEZ.PUNKT & 0,05 \\
RLW UG & 00 \\
RLW OG & 800 \\
LINBER UG & $\left({ }^{\circ}\right)$ \\
LIN.GR & $\left({ }^{\circ}\right)$ \\
KAL.FAKTOR & 45 \\
STD.W. & 180 \\
NORM.B. & 1,0 \\
NORM.B. & 0,0 \\
STEIG & 0,005 \\
SCHNITTP & \\
EP LIM & \\
\hline
\end{tabular}

\section{Methoden und Geräte}

Als Referenzmethode diente die von der Internationalen Gesellschaft für Hämatologie als solche empfohlene Methode (7). Hämoglobin wurde mit einer Testkombination bestimmt (Art.-Nr.124729 Boehringer Mannheim). Für die von Hand ausgeführten Bestimmungen wurde ein Photometer (PM 4 Zeiss) verwendet. Die TPTZ-CitratMethode wurde auf einen RA-1000 und einen SMAC II adaptiert (beide TECHNICON), Fließschema und Programmvorschlag siehe Abb.1 und Tab.1.

\section{Reagenzien}

Diese wurden von Merck mit Reinheitsgrad pro analysi bezogen.

Ansatz des Reaktionsgemisches:

2,4,6-Tri-2-pyridyl-1,3,5-Triazin (TPTZ)

(Merck Nr.10238)

L(+)Ascorbinsäure p.a.

(Merck Nr.127)

Citronensäure $\times 1 \mathrm{H}_{2} \mathrm{O}$ p.a.

(Merck Nr.244)

Bidestilliertes Wasser

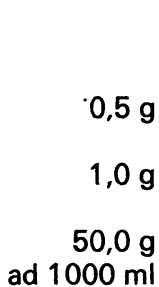

Als Leerwertlösung wurde die gleiche Lösung ohne TPTZ verwendet. Beide Lösungen sind kühl und verschlossen aufbewahrt mindestens 3 Wochen stabil.

Für den RA-1000 wurde 1 Tropfen Wetting Agent W (TECHNICON Nr.T 21-1298) auf 6,5 ml Reagenz vor Gebrauch zugesetzt. Für den Smac II wurde 1,0 ml Wetting Agent NWA (TECHNICON Nr.T 21-0813-17) pro $200,0 \mathrm{ml}$ Reagenz zugesetzt. Bei Wellenlänge $600 \mathrm{~nm}$ wurde gemessen. Zum Eichen wird TECHNICON Kalibrator Nr.T 03-1168-60 Setpoint Cal 2 oder ein wäßriger Standard (Boehringer) verwendet.

\section{Probenmenge}

Für die zugesetzte Probenmenge steht ein Spielraum von $1: 6$ bis $1: 12$ Teile Serum zu Reagenz zur Verfügung. Das Mischungsverhältnis von Probe zu Reagenz beträgt $1: 6,5$ beim Smac II und 1:12 beim RA-1000.
pH-Wert

Citronensäure in Wasser gelöst ergibt einen $\mathrm{pH}$ von 1,61.7. Serum bzw. Plasma mit Citrat-Ascorbat-Puffer im Verhältnis 1:6 gemischt ergibt einen $\mathrm{pH}$ von $2,2-2,4$. Der pH-Wert schwankt in diesem Bereich je nach Probe. Die Farbentwicklung ist in diesem Bereich konstant, so daß kleine $\mathrm{pH}$-Schwankungen, die durch Probenmaterial verursacht werden, das Analysenergebnis nicht beeinflussen.

$\mathrm{pH}$-Veränderungen durch Zusatz von $\mathrm{HCl}$ in den Bereichen zwischen 1,9 und 3,1 verändern das Analysenergebnis nicht. Auf einen zusätzlichen Puffer, der den pH konstant hält, kann verzichtet werden.

\section{Reaktionsgeschwindigkeit}

TPTZ reagiert mit dem Eisen so schnell, daß die Reaktion zu einer Eisenbestimmung im Serum in ca. $30 \mathrm{sec}$ abgeschlossen ist. Somit sind keine langen Inkubationszeiten nötig. Es kann bei $25^{\circ} \mathrm{C}$ ebenso gut wie bei $37^{\circ} \mathrm{C}$ gemessen werden. Im Gegensatz dazu dauert die Farbentwicklung mit z.B. Ferrozin $5-30 \min (3,19,22)$.

Der Zusatz von Ascorbat ist für die Farbentwicklung nicht nötig, da TPTZ auch mit dreiwertigem Eisen reagiert, wenn auch etwas langsamer als mit zweiwertigem (23). Ascorbat unterstützt aber die Freisetzung von Eisen aus der Transferrinbindung. Die Gesamtreaktion ist somit schneller und vollständig (1).

\section{Ergebnisse und Diskussion}

\section{Spezifität}

1. Einfluß von Kupfer: Einer Probe mit einem Eisengehalt von $51 \mu \mathrm{g} / \mathrm{dl}$ wurde Kupfer in steigenden Konzentrationen von $50-1000 \mu \mathrm{g} / \mathrm{dl}\left(\mathrm{CuCl}_{2}\right.$-Lösung $)$ zugesetzt und anschließend Eisen in 5fach-Werten mit TPTZ-Citrat und

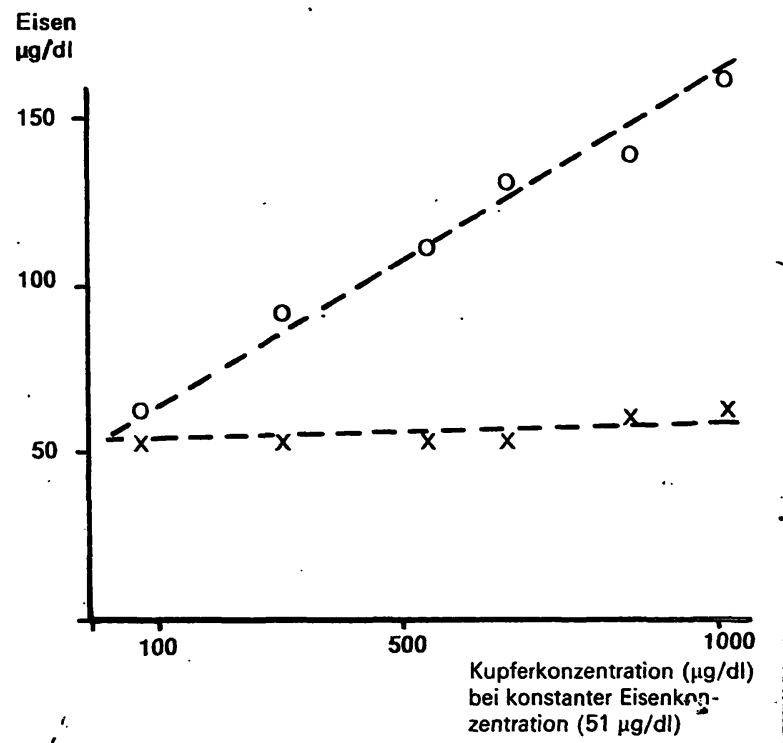

$A b b$. 2: Einfluß der Kupferkonzentration (Abscisse) auf die Ergebnisse der Eisenbestimmung (Ordinate) bei den Bestimmungsmethoden mit TPTZ-Citrat $(x--x)$ bzw. FerrozinGuanidin $\left(\mathrm{O}-\mathrm{O}_{-} \mathrm{O}\right.$ ). Ein Serum mit bekanntem Eisengehalt von $51 \mu \mathrm{g} / \mathrm{dl}$ und steigender Konzentration von $\mathrm{CuCl}_{2}$ wurde auf Eisen analysiert 
Ferrozin/Guanidin (14) bestimmt. Das Resultat ist in Abb. 2 dargestellt. Bei der Methode mit Ferrozin errechnet sich für $100 \mu \mathrm{g} / \mathrm{dl}$ Kupfer ein falscher Eisenwert von $+15 \mu \mathrm{g} / \mathrm{dl}$, mit TPTZ-Citrat dagegen nur von $+2 \mu \mathrm{g} / \mathrm{dl}$. Dieser Befund stimmt mit der Literatur überein (4).

2. Einfluß von Hämoglobin: Hämoglobin wurde in steigender Konzentration bis $\mathbf{4}$ g/l verschiedenen Proben zugesetzt. Der Eisengehalt mit und ohne Zusatz von Hämoglobin wurde bestimmt, es ergab sich kein Unterschied. Daraus kann der Schluß gezogen werden, daß Hämolyse in dieser Größenordnung ohne Einfluß auf die Eisenbestimmung ist (siehe Tab.2). Inwieweit Eisen in hämolytischem Probenmaterial nach Tagen freigesetzt wird, bleibt dahingestellt.

3. Einfluß von EDTA: EDTA interferiert bei der TPTZCitrat-Methode in Abhängigkeit von der Konzentration. EDTA stört auch die Eisenreaktion mit Ferrozin und anderen Chromogenen empfindlich $(7,14-16)$.

4. Detergentien: Zusätze von Detergentien, wie sie für manche Analysensysteme verwendet werden, wie Brij, Triton, Wetting Agents, beeinflussen die Farbreaktion nicht, allerdings wird die Haltbarkeit der Reagenzien be-

Tab.2: Nachweis, daß Hämoglobin (Hb) die Eisenbestimmung nicht stört. 21 Seren wurden geteilt, der einen Hälfte wurde Hämoglobin, der anderen Hälfte 0,9\% NaCl-Lösung zugesetzt. Die Hämoglobin- und Eisenkonzentrationen (Doppelwerte) sind aufgeführt. Hämoglobin geht in die Eisenreaktion nicht ein

\begin{tabular}{|c|c|c|c|c|c|}
\hline \multirow{2}{*}{$\begin{array}{l}\text { Probe } \\
\text { Nr. }\end{array}$} & \multicolumn{3}{|c|}{ 1. Teil der Probe } & \multicolumn{2}{|c|}{ 2. Teil der Probe } \\
\hline & $\begin{array}{l}H b \\
(g / l)\end{array}$ & $\begin{array}{l}\text { Eisen } \\
(\mu g / d l)\end{array}$ & & $\begin{array}{l}\mathbf{H b} \\
(\mathbf{g} / \mathbf{l})\end{array}$ & $\begin{array}{l}\text { Eisen } \\
(\mu g / d I)\end{array}$ \\
\hline $\begin{array}{r}1 \\
2 \\
3 \\
4 \\
5 \\
6 \\
7 \\
8 \\
9 \\
10 \\
11 \\
12 \\
13 \\
14 \\
15 \\
16 \\
17 \\
18 \\
19 \\
20 \\
21\end{array}$ & $\begin{array}{l}1,66 \\
1,66 \\
2,20 \\
2,20 \\
2,21 \\
2,21 \\
2,94 \\
2,94 \\
3,3 \\
3,3 \\
3,68 \\
3,68 \\
3,7 \\
4,00 \\
4,00 \\
4,00 \\
4,05 \\
4,05 \\
4,40 \\
4,40 \\
4,4\end{array}$ & $\begin{array}{l}20 / 27 \\
25 / 23 \\
66 / 78 \\
76 / 86 \\
16 / 22 \\
21 / 30 \\
78 / 73 \\
80 / 71 \\
53 / 57 \\
33 / 36 \\
24 / 21 \\
25 / 15 \\
66 / 62 \\
38 / 42 \\
78 / 82 \\
66 / 74 \\
59 / 69 \\
53 / 71 \\
11 / 13 \\
16 / 17 \\
31 / 37\end{array}$ & $\cdot$ & 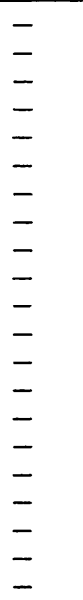 & $\begin{array}{l}27 / 31 \\
29 / 30 \\
66 / 81 \\
68 / 79 \\
22 / 25 \\
20 / 33 \\
69 / 75 \\
62 / 74 \\
60 / 60 \\
40 / 38 \\
23 / 27 \\
24 / 26 \\
66 / 62 \\
40 / 42 \\
85 / 81 \\
70 / 73 \\
68 / 61 \\
63 / 63 \\
13 / 14 \\
14 / 15 \\
36 / 34\end{array}$ \\
\hline \multicolumn{2}{|c|}{$\begin{array}{l}\text { Mittelwert } \bar{x} \\
\text { Standard- } \\
\text { abweichung s }\end{array}$} & 45,9 & & & 47,35 \\
\hline
\end{tabular}

Tab. 3: Präzisionskontrolle von Tag zu Tag $(n=25)$ für die TPTZCitrat-Methode in verschiedenen Meßbereichen. Kont und Sequ bezeichnen lyophilisierte, kommerzielle Kontrollseren. Poolseren sind ausgesuchte, gepoolte Seren, die bis zur Analyse in separaten Gefäßen bei $+4^{\circ} \mathrm{C}$ aufbewahrt wurden

\begin{tabular}{lcccccr}
\hline \multicolumn{5}{c}{ Kont } & Sequ & \multicolumn{4}{c}{ Poolseren } \\
\hline $\bar{x}(\mu \mathrm{g} / \mathrm{dl})$ & 89 & 258 & 98 & 25 & 10 & 5 \\
$\mathrm{VK}(\%)$ & 3,2 & 2,8 & 3,5 & 3,9 & 9 & 11 \\
\hline
\end{tabular}

grenzt, weil sich mit der Zeit Trübungen entwickeln können.

\section{Methodenvergleich}

Mit der TPTZ-Citrat- und der Referenzmethode wurden die Kollektive A, B und C parallel analysiert (siehe auch Probenmaterial in Material und Methoden). Die Ergebnisse sind in Abb. $3(\mathrm{~A}-\mathrm{C})$ dargestellt.
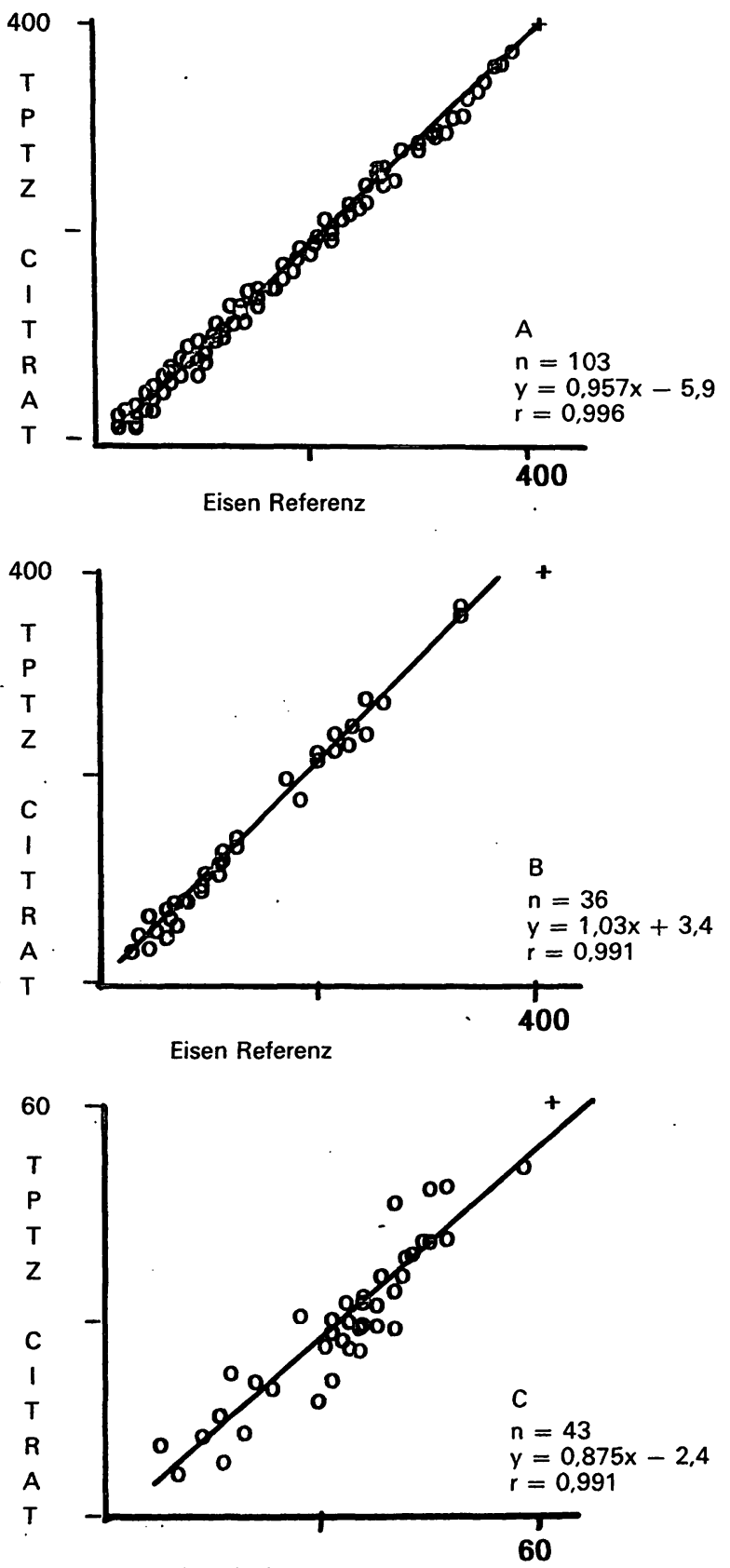

Eisen Referenz

Abb. $3(A-C)$ : Methodenvergleiche zwischen der Referenzmethode (Abszisse) und der TPTZ-Citrat-Methode (Ordinate). Die Ausgleichsgeraden sind mit der Hauptkomponentenschätzung berechnet. A bezeichnet unausgewählte Proben; $B$ Proben von schwerkranken Patienten; C Proben mit Eisen $<50 \mu \mathrm{g} / \mathrm{dl}$ 
Tab. 4: Richtwerte für Eisen im Serum bzw. Plasma in $\mu \mathrm{g} / \mathrm{dl}$ mit verschiedenen Methoden ermittelt. Es wurden Methoden ohne Enteiweißung (direkt) durchgeführt. Die Kollektive sind vergleichbar (siehe Material und Methoden)

\begin{tabular}{lll}
\hline & $\begin{array}{l}\text { 95\%-Per- } \\
\text { Zentile }\end{array}$ & Median $\overline{\mathbf{x}}$ \\
\hline $\begin{array}{l}\text { TPTZ-Citrat, direkt } \\
\text { Männer }(n=141)\end{array}$ & 158 & 89 \\
$\begin{array}{l}\text { Frauen }(n=165) \\
\text { Bathophenanthrolin- }\end{array}$ & 179 & 89 \\
$\begin{array}{l}\text { Azetat, direkt } \\
\text { Männer }(n=405)\end{array}$ & 189 & 94 \\
\hline $\begin{array}{l}\text { Ferrozin-Guanidin, direkt } \\
\text { Männer ( } n=251)\end{array}$ & 180 & 102 \\
\hline
\end{tabular}

\section{Präzision und Richtigkeit}

Die Präzision wurde mit käuflichen Kontrollseren von Tag zu Tag geprüft. Die Eisengehalte lagen bei 89 und $258 \mu \mathrm{g} /$ dl. In dieser Serie ergab sich ein VK $<3,2 \%$. Um die unteren Bereiche zu prüfen, wurden Patientenseren mit niedrigen Eisenwerten gesammelt, gepoolt und dann von Tag zu Tag in der Präzisionskontrolle analysiert. Die Analysenergebnisse sind in Tab. 3 zusammengestellt. Die Richtigkeit weicht um $<4 \%$ vom Sollwert ab.

\section{Normbereich}

Für die TPTZ-Citrat-Methode haben wir Richtwerte ermittelt, siehe Tab.4. Zum Vergleich sind Werte anderer Methoden (Chromogene und Puffer) aufgeführt, die an vergleichbaren Kollektiven von uns erhalten wurden (24). Der Median und der obere Richtwert sind bei der TPTZCitrat-Methode niedriger. Wir interpretieren dies als das Ergebnis besserer Spezifität.

\section{Schlußbemerkung}

Folgende Gesichtspunkte waren für die Auswahl von Chromogen und Puffer maßgebend:

1. Auf die Enteiweißung haben wir verzichtet, denn in vielen Seren erhielten wir falsch-niedrige Ergebnisse. Das heißt, daß der Fehler der Eisenabsorption bei EnteiweiBung oder Dialyse besonders bei niedrigen Eisenwerten störend ins Gewicht fällt. Durch den Verzicht auf Enteiweißung wird die Methode außerdem handlicher, die Gefahr der Verunreinigung mit Eisen beim analytischen $\mathrm{Ma}$ nipulieren wird minimiert und der Bedarf an Probenmaterial ist klein (5).

2. Es wurde ein Chromogen gewählt, bei dem Kupfer nur geringfügig stört. In der klinischen Praxis haben immer wieder hohe Kupferwerte bei Anämie gestört.

3. Die Kosten für Chemikalien sollten dem Zweck angemessen sein. Einige Chromogene und vor allem Puffer sind extrem teuer und nicht unbedingt besser als preiswertere.
Schriftum:

1. ICHIDA, T., OSAKA, T., KOJIMA, K.: A simple method for the determination of serum iron. Clin. Chim. Acta 22, $271-275$ (1968).

2. GARCIC. A. A highly sensitive, simple determination of serum iron using chromazurol B. Clin. Chim. Acta 94, 115-119 (1979).

3. CERIOTTI, F., CERIOTTI, G.: Improved Direct Specific Determination of Serum Iron and Total lron Binding Capacity. Clin. Chem. 26. 327-331 (1980).

4. COLLINS, P. F., DIEHL, H.: 2,4,6-Tripyridyl-s-triazine as a Reagent for Iron. Anal. Chem. 31, 1862-1867 (1959).

5. SOLEM, E., SEIFFERT, U. B. u.a. zur Veröffentlichung eingereicht.

6. YEE, H. Y., ZIN, A.: An Automated Procedure for Serum Iron and Total lron-Binding Capacity with use of Ferrozine. Clin. Chem. 17. 950-953 (1971).

7. International Committee for Standardization in Hematology. Proposed Recommen dations for Measurement of Serum Iron in Human Blood. Blood 37, 598-600 (1971). 8. SCHADE, A. L., OYAMA, J., RINHART, R. W., MILLER, J. R.: Bound Iron and unsaturated Iron-Binding Capacity of Serum; Rapid and reliable Quantitative Determination. Proc. Soc. Exper. Biol. Med. 87, 443-448 (1954).

9. EISENWIENER, H. G., RIETZ, P, SCHÄFER, P.: Die Bestimmung des Eisens mit der Guanidinchlorid/Ferrozin-Methode. J. Clin. Chem. Clin. Biochem. 17, 149 (1979) 10. DAVID, R. M., SHIHABI, Z. K.: Diluent in the Technicon SMAC Assay for Iron Modified to avoid Serum Precipitation. Clin. Chem. 30, 579 (1984).

11. MORI, L., BEKKERING, A., TRAINI, J., VANDERLINDEN, L.: Ferrozine Iron and total Iron Binding Capacity Method Adapted to the ABA-100 Bichromatic Analyzer. Clin. Chem. 27, 1441-1444 (1981).

12. YOUNG, D. S., HICKS, J. M.: Method for the automatic determination of serum iron. J. Clin. Path. 18, 98-102 (1965).

13. ESKELINEN, S., HAIKONEN, M., RÄISÄNEN, S.: Ferene-S as the chromogen for Serum Iron Determinations. Scand. J. clin. Lab.. Invest. 43, 453-455 (1983).

14. VIOLLIER, M. A., GSCHWIND, H., SCHÄFER, P. : Neue Serumeisenbestimmung auf dem GSA II. Lab.med. 4, 240 - 244 (1980)

15. FOWLER, S. A., PAULSON, D., OWEN, B. A., OWEN, W. G.: Binding of lron by Factor IX. J. Biol. Chem. 261, 4371-4372 (1986).

16. KOOPMAN, B. J., HINDRIKS, F. R., LOKERSE, Y. G., WOLTHERS, B. G, ORVERDIJK, J. F.: Injurious Effect of EDTA Contamination on Colorimetry of Serum Iron Clin. Chem. 31, 2030-2032 (1985).

17. MARTIN, R. B., SAVORY, J., BROWN, S., BERTHOLF, R. L., WILLS, M. R. Transferrin Binding of $\mathrm{Al}^{3+}$ and $\mathrm{Fe}^{3+}$. Clin. Chem. 33, 405-407 (1987).

18. STOOKEY, L. L.: Ferrozine - A New Spectrophotometric Reagent for Iron. Analytical Chemistry 42, 779-781 (1970).

19. ARTISS, J. D. VINOGRADOV, S, ZAK, B. Spectrophotometric Study of Several Sensitive Reagents for Serum Iron. Clin. Biochem. 14, 311-315 (1981).

20. GIOVANNIELlO, Th. J., DiBENEDETTO, G., PALMER, D. W., PETERS, T., Jr.: Fully and semiautomated methods for the determination of serum iron and total ironbinding capacity. J. Lab. Clin. Med. 71, 874-883 (1968).

21. RICE; E. W. FENNER, H. E.: Study of the ICSH proposed Reference Method for Serum Iron Assay: Obtaining optically clear Filtrates and Substitution of Ferrozine. Clin. Chim. Acta 53, 391 - 393 (1974)

22. LEVINSON, S. S.: Manual Ferrozine Kit Method for Iron and Total Iron-Binding Capacity Adapted and Evaluated for Use with Discrete Mechanized Analyzers. Clin. Chem. 26, 671 - 672 (1980)

23. COTTON, F. A., WILKINSON, G.: Anorganische Chemie. Verlag Chemie, Weinhaim (1974).

24. SEIFFERT, U. B.: Unveröffentlichte Ergebnisse.

Anschrift für die Verfasser:

Prof. Dr. med. U. B. Seiffert Zentrallabor des Zentrums für Innere Medizin, Klinikum der Johann Wolfgang Goethe-Universität Theodor-Stern-Kai 7

6000 Frankfurt 


\section{Bei Licht besehen (2)}

Am Anfang war das Licht...

Mit dem Licht beginnt die geordnete und lebendige Welt. Das Licht hat Forscher und Wissenschaftler schon immer fasziniert. Ihre Entdeckungen und Entwicklungen haben unser Leben revolutioniert. Die Steuerung und Nutzbarmachung von Licht stellt für jede Generation eine Herausforderung an ihr wissenschaftlich-innovatives Denken dar.

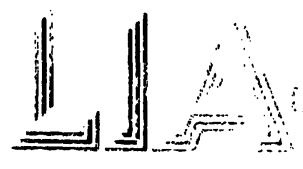

Lumineszenz-Immuno-Assays

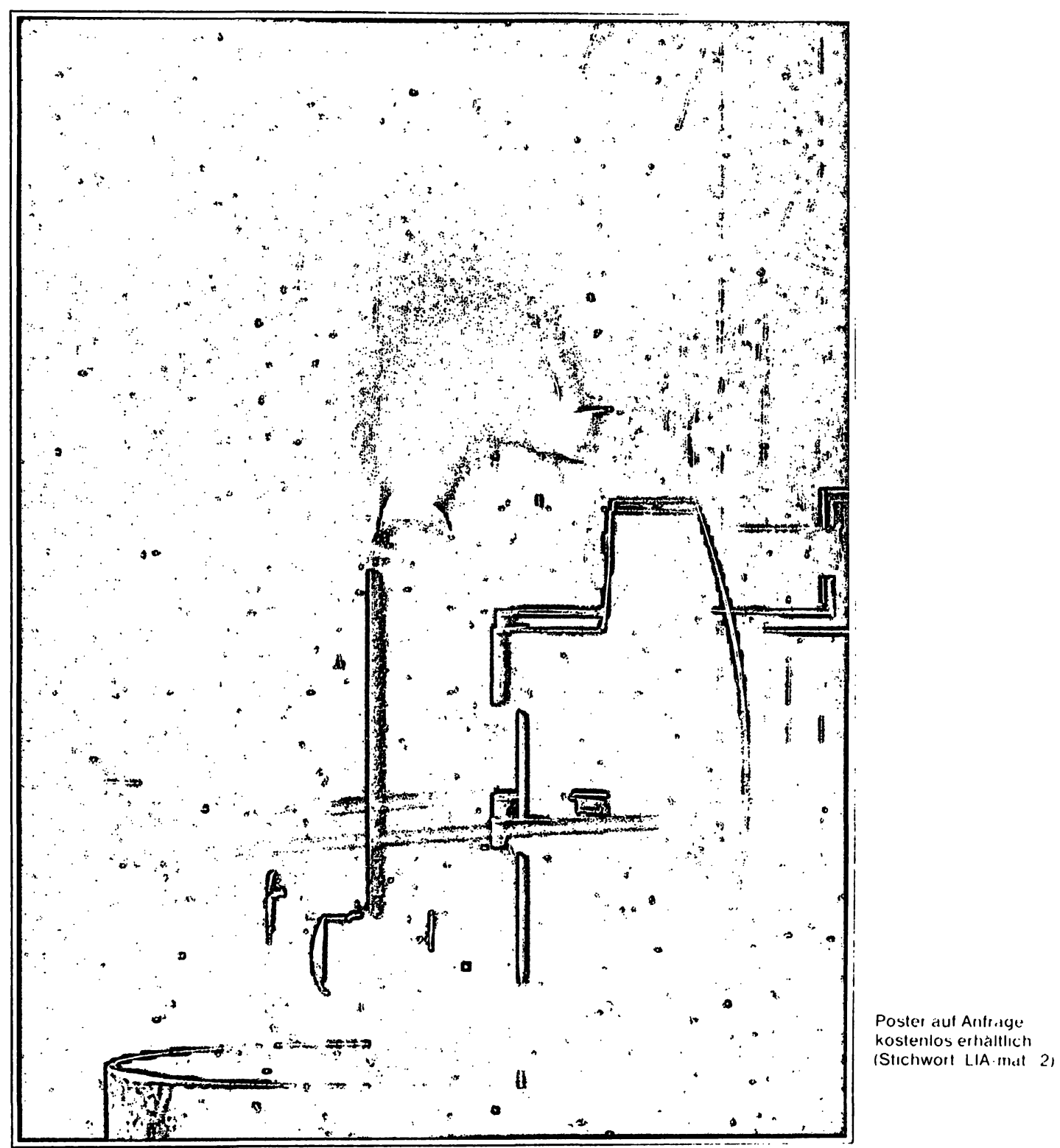

\section{Sir Humphry Davy}

entdeckt den elektrischen Lichtbogen.

Diese neue Lichtquelle wird später in

Leuchttürmen eingesetzt:

Die Seeschiffahrt wird sicherer.
1987 Mallinckrodt Diagnostica

stellt LIA-mat 'Lumineszenz-ImmunoAssays vor. Chemisch erzeugte Lichtsignale eröffnen neue Wege und Perspektiven in der Labor-Diagnostik. 
